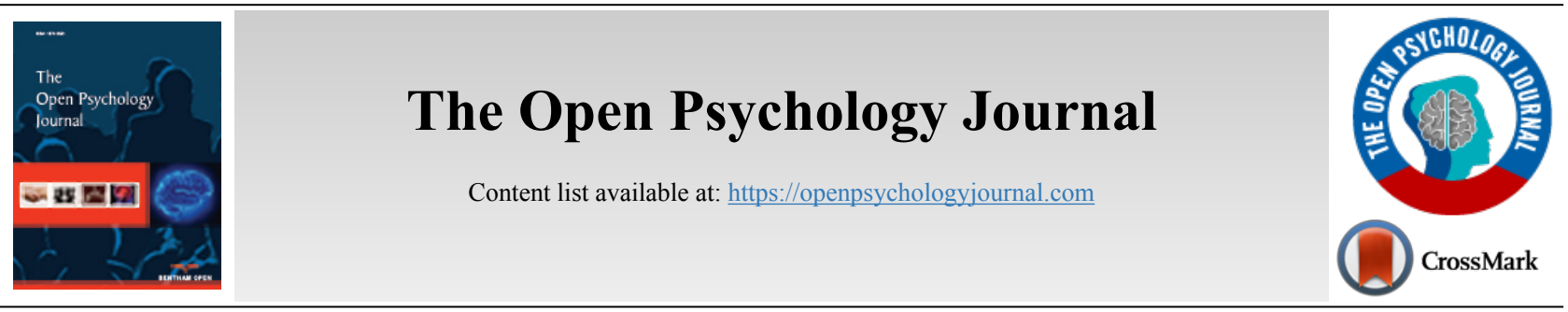

RESEARCH ARTICLE

\title{
Vulnerability to Child Maltreatment and Neglect in Italy: A Proposal of an Indicator
}

\author{
Paola Cardinali ${ }^{1, *}$, Giovanna Badalassi ${ }^{2}$, Valeria Emmi $^{3}$, Federica Gentile $^{4}$ and Laura Migliorini ${ }^{5}$ \\ ${ }^{\prime}$ Department of Education Science, University of Genoa, Genoa, Italy \\ ${ }^{2} \mathrm{CESVI}$ (NGO), Advocacy Coordinator, Italy \\ ${ }^{3}$ CESVI (NGO), Consultant, Italy \\ ${ }^{4}$ Department of Gender Studies, University of Missouri, Missouri, United States
}

\begin{abstract}
:
Background:

Child maltreatment and neglect is a significant social problem. Present work addresses the important issue of quantifying the vulnerability to child maltreatment and neglect, proposing the application in the Italian context of a new General Index on Vulnerability to Maltreatment and Neglect to achieve a more comprehensive understanding of this phenomenon.
\end{abstract}

\section{Methods:}

The paper presents the first findings of the vulnerability among Italian minors, obtained through the new General Index, based on a set of 65 indicators that already existed at the regional and national levels.

Results:

The General Index summarizes both the weaknesses of territory in terms of risk factors and its ability to react according to the policies and public services. A global index could be useful for allocating resources and monitoring progress. To understand and ensure the effectiveness of preventive interventions, it is essential to build both an overall picture at the national and regional levels.

\section{Conclusion:}

This new index could give policymakers information on where to direct their efforts to prevent child maltreatment.

Keywords: Child neglect, Risk factors, Prevention, Ecological perspective, Italy, Child maltreatment.

\begin{tabular}{|l|l|l|l|}
\hline Article History & Received: March 11, 2020 & Revised: May 28, 2020 & Accepted: June 03, 2020 \\
\hline
\end{tabular}

\section{INTRODUCTION}

Child health and welfare represent a key social indicator of the well-being of a society, and child maltreatment represents a major threat to children's well-being [1]. In particular, child neglect is the most common form of maltreatment and abuse, and although pervasive and sometimes life-threatening, it is nonetheless often difficult to identify as it is characterized more by the absence of something than by its presence. An Italian survey, conducted by the Authority for Childhood and Adolescence, CISMAI (the network of Italian association and stakeholders concerned with child protection against abuse and neglect) and Terre des Hommes reported that among the

\footnotetext{
* Address correspondence to this author at the, Department of Education Science,
} University of Genoa, Genoa, Italy; E-mail: paola.cardinali@unige.it minors in the care of social services for maltreatment, the largest percentage $(47.1 \%)$ of minors have experienced physical and psychological negligence [2]. According to these reports, this figure is higher than the European average (35\%) and lower than that of the United States (60\%).

In the literature on child maltreatment, much attention is given to physical and sexual abuse, even though the consequences of neglect may be equally dangerous. In fact, there are indications that neglected children have more profound developmental and psychological deficits than abused children $[3,4]$, and children who are not adequately supervised are at a significantly increased risk of death [5]. Furthermore, neglected children could suffer from a wider range of types of maltreatment than those who are not victims of neglect [6]. 
However, child neglect is still the least studied of all forms of child abuse $[7,8]$.

Child neglect could be considered a form of child abuse that refers to the omission of the caretaking behaviors necessary for a child's healthy development, for example, poor quality of supervision, inadequate or insufficient availability of food, poor school attendance, and lack of required medical attention, while other forms of abuse typically have to do with harmful acts committed against the child [6]. Thus, neglect, or the failure to provide for the development and well-being of the child, includes both isolated incidents and a pattern of repetitive behavior over time [9].

In the present study, the neglect and maltreatment issue, according to a systemic model, in which parents' behavior and attitude are considered in relation to family and socio-cultural context, was approached. Neglect is best viewed from an ecological perspective in which child, parent, family, and community factors all play a role in the well-being of a child [10 - 13]. According to the socio-ecological model of Bronfenbrenner, neglect and maltreatment could be analyzed considering the following: the characteristics of the child and the family (i.e.., the microsystem); the interrelation between different contexts of life (i.e.. the mesosystem); the characteristics of the living environment (i.e., the exosystem); and the interaction between the family system and the availability of support and resources in the community (community level) as well as the political and cultural context. These levels range from the proximal child environment to a more distal social structure and to the wider culture [14]. As the actions of the parent (or lack of action) are considered to be the cause of neglect, action or inaction on the part of the community, society and professionals can also contribute to neglect [15]. The idea behind the present work is that violence against children, even by omission, is a widespread phenomenon in every social class but is strongly affected by the poverty and unemployment conditions present in the community due to the fragmentation and reduction of the support network provided from social assistance and health services.

Cultural differences in parenting expectations can lead to divergent definitions of what constitutes neglectful behavior [16]. Some authors describe the 'Italian way' of thinking about parenting, such that parenting is not thought to exert direct effects on child growth and development [17]. Parental behavior that in another culture could be seen as a way to increase independence could be considered by an Italian mother to be premature or lacking. Racial disproportionality in child maltreatment may be connected to a divergence between the beliefs of ethnic groups and those of social workers [18]. A recent qualitative study aptly describes the complexity of defining neglect and highlights that the construction of the concept of child neglect could be not always child-centered [19]: a child whose physical and supervisory needs were not being met could be positioned as 'not neglected' if the parent was seen as overburdened. In contrast, a child whose physical, supervisory, and training needs were apparently all being met could be positioned as unloved and, therefore, 'neglected' if a parent was seen as underinvested. However, the Neglect toolkit for practitioners, edited by East Sussex County Council in 2017 [20], underlines the importance "to keep the needs of the children in central focus and strive to understand their world" (p.8).

States differ in how they define neglect; some studies [21] attribute this definitional variation to the complexity of child maltreatment, a lack of policy uniformity in how to respond to child maltreatment, and the multitude of legal systems involved. According to a recent study, some states have identified minimal features in their definitions; a few included aspects, such as emotional neglect, while the majority focused on the keystone components of physical neglect [22].

The types of neglect that are most frequently described in the literature are as follows: (a) physical neglect, referring to the failure of parents to meet children's physical needs, for instance, by providing inadequate nutrition or not seeing a doctor when a child has medical care needs; (b) emotional neglect, referring to the failure of parents to meet children's emotional needs, for instance, by not showing affection to the child; (c) educational neglect, referring to the failure of parents to provide the care that is necessary to secure a child's education, for instance, by allowing a child to be chronically absent from school; and (d) supervisory neglect, referring to the failure of parents to provide the child with adequate protection from harmful people or situations [23]. Supervisory neglect is consistently identified as the most common form of neglect [24], and neglect recidivism commonly recurred as "lack of supervision" [25].

\subsection{Risk Factors and Child Neglect}

The risk of child maltreatment is influenced by individuallevel parental characteristics, family-level factors, and the broader social context. In literature review about the risk factors of neglect, Some authors underscore that multiple risk factors are involved in the occurrence of child neglect, confirming that child neglect is more likely to be determined by multiple causes than by a single specific risk factor [7]. Furthermore, they highlight that child neglect is perceived as the result of a complex interplay of risk factors present in the child's environment.

Research on child neglect is limited because, in a substantial number of studies, variables were examined as risk factors for child maltreatment in general and not specifically for child neglect $[7,26]$. In fact, the identification of risk factors is not simple; sometimes, for example, food insecurity is a trigger for uncovering other risks. This situation arises when the relevance of identifying appropriate tools is considered [27]. However, some studies have identified risk factors for neglect. Some authors reviewed the published literature on risk factors for child neglect and identified variables at different levels [28]: unplanned conceptions at the demographic level; verbal and nonverbal mother-child interaction at the behavioral level; and low self-esteem, impulsivity, substance abuse diagnosis, lack of social support, and daily stress at the psychological level. Another study underlines the importance of considering parent-level variables, such as parent distress, in evaluating the consequences of neglect and point to the importance of 
considering contextual factors when identifying children at the highest risk following neglect [29]. At the family and community levels, some authors underline parents' depression, addiction and mental health problems, poverty, and social isolation [30]. The European Report on Preventing Child Maltreatment, published in 2013 by the European Regional Office of the WHO (World Health Organization), highlights some risk and protective factors against violence [31]. It outlines that these factors could concern the individual level (e.g., parents who are young, are single, have low socioeconomic status, have low education levels, have poor mental health, or have alcohol and drug abuse), the relationship level (e.g., family conflict, intimate partner violence), the community level (e.g., economically deprived communities, lack of social capital) and societal levels (e.g., social and cultural norms supporting physical punishment of children).

Some authors found that the strongest indicators of parent and family-related risk factors were current mental/psychiatric problems, a history of mental/psychiatric problems or childhood abuse, age factors, single parenthood, low family SES, large family size, and problematic family behavior [32, 33]. According to other studies [34], parental characteristics consistently cited as risk factors for child abuse and neglect include young maternal age, low maternal educational achievement, parental history of abuse and neglect, parental history of alcohol and drug abuse, and maternal depression [35, 36]. Some authors highlight that the rates of paternal depression are twice as high in families that report neglectful behavior compared to families that report no such incidents [37]. At the family level, single-parent, mixed (step families), and large families, and the presence of domestic violence were found to be linked to an increased risk of child maltreatment $[38,39]$. Irregular preschool attendance, possibly the result of family instability, significantly increased the risk of subsequent allegations of child neglect [34]. At the upper level, economic, chronic or daily stress seem to increase the risk of neglect [32]. Poverty is a particularly salient issue because research has established a relationship between poverty and neglect [40]; however, there is no strict causality in this relationship, since there are also families who live in poverty who do not neglect their children. The circumstances and stress associated with a lack of money can detrimentally impact positive parenting behaviors; however, in some situations, children and families develop resilience $[41,42]$. This could be due to the presence of protective factors that increase an individual's resilience and could mitigate the consequences of these stressful circumstances [43]. In these cases, perhaps the child welfare system could be viewed as part of the environmental context that influences children, caregivers and child-caregiver relationships, promoting resilience among this particularly vulnerable subgroup of children.

The association between risk factors and specific types of neglect (such as physical, emotional, supervisory, and educational) are less described in the literature [7]. A recent study reports that risk factors for educational neglect could be caregiver mental health issues, a lack of family support, and a generally chaotic and suboptimal home environment [44]. Supervisory neglect could be associated with caregiver substance abuse, overcrowding in the home [45] and low income [46]. Physical neglect cases are high among families facing economic hardship [47].

Protective factors have not been studied as extensively as risk factors, but in the literature, the stress-buffering effect of social support in helping individuals cope with stressful life events is evident [48]. Some studies highlight the importance of medical assistance, and in particular, of pediatricians' role in prevention [49, 50]. Some authors found that two-parent households, high levels of maternal education, and high levels of social support reduce the risk of child maltreatment. Involvement in child activities and self-efficacy also plays a role in reducing the risk of neglect $[39,51]$. Paying attention to the protective factors allows for a change in perspective and the ability to concentrate on the resources present to face a complex phenomenon such as neglect. In line with this idea, the capability approach [52] is a very useful theoretical framework with a multidimensional perspective.

This theory, developed in the 1980s by Nobel Prize winner Amartya Sen and further elaborated by Martha Nussbaum, has already been applied to the Human Development Indicator (UNPD HDI). The capability approach is based on what people are capable of doing and being [53], but according to Sen, a person's well-being is defined not only by the achievement of relevant functioning but also by the forms of functioning that hypothetically could be put into action. According to Sen, this aspect characterizes the capabilities or freedoms from which the person chooses among various possibilities. Capabilities and functioning depend on a person's individual characteristics in terms of resources and how these resources can be used [54, 55]. This theory places the evolution of human beings at the center of economic policies and public action, focusing on the well-being of human beings rather than on the production of wealth; from this perspective, it represents a sharp contrast to the Gross Domestic Product (GDP) as an indicator of the level of "development" of a country. It does not, of course, deny the importance of material well-being but rather underlines the need to combine poverty and material deprivation indicators with other types of indicators related to, for instance, physical and mental health, affectivity, leisure activities, respect, diversity and identity [56].

Amartya Sen's work focuses on the individual's capabilities, as well as on the contributing factors and contextual interaction; in line with this perspective in this work, we chose to analyze not only risk factors for child neglect but also services to build an overall picture of the phenomenon and of the current preventive interventions. Child welfare services play an important role in promoting the wellbeing of children who have suffered child maltreatment [57].

Children who are provided with care by the services report less recurrence of maltreatment [58], and therapy for both the parent and the child also reduces the chances of recurrence [59].

For the purpose of this research, a list of capabilities selected among those proposed by Amartya Sen was adopted among those that could best represent the risk factors indicated in the European Report on Preventing Child Maltreatment, published in 2013 by the European Regional Office of the 
WHO (World Health Organization) [31]. Once the risk factors were classified by capacity, a selection was made of the indicators that could best represent them as well as indicators of the services offered on the grounds that were dedicated to preventing and treating those risk factors. Theories from multiple research fields (e.g., human rights, health policy, social and developmental psychology) suggest the need for development measures and indicators to achieve a comprehensive understanding of child neglect, risk and protective factors, and their balance. Processing a synthesis of indicators could not only be a particular way of applying the capability approach but also a relevant framework for embracing complexity over time and multidimensionality [60].

According to the World Health Organization (2007), a public health approach to prevent child maltreatment and neglect requires the identification of risk and protective factors [61]. In Italy, there is not an instrument that measures maltreatment and neglect; the present study tries to fill this gap addressing the important issue of quantifying the risk of child maltreatment and neglect. It proposes the application in the Italian context of a new General Index on Vulnerability to Maltreatment and Neglect to achieve a more comprehensive understanding of this phenomenon, its risk factors, local services, and their balance. As shown below, the index has been based on a set of indicators that already exist at the regional and national levels. It includes the presence of both risk factors for child neglect and local services, which can provide an answer.

\subsection{The Italian Context}

Italy is a southern European country with a population of approximately 60.5 million inhabitants, 9.9 million of whom are minors (i.e., under the age of 18 years; $16.4 \%$ ) (National Statistics Institute 2017). From a socio-economic perspective, Italy is classified among the countries with the highest quality of life: it is a member of the G7; and it ranks 28th among the 189 countries in the Human Development Index (HDI).

However, this macro situation hides big territorial differences among the 20 regions that compose the country, especially between the North and the South: simply considering the employment rate, which is $66.7 \%$ in the North compared to $44.0 \%$ in the South (National Statistics Institute, 2017 ), and the absolute poverty index, which is $5.4 \%$ and $10.3 \%$, respectively (National Statistics Institute, 2017).

The 2008 economic crisis compounded the country's existing structural problems, such as low productivity, an aging population, corruption and criminality, giving rise to a high level of social discontent. The most telling example of these difficulties is certainly related to the poverty index, which, in 2017, reached its highest level since 2005.

Children's maltreatment and neglect in Italy occurs within this overall socio-economic framework. It is a social issue that is very difficult to estimate, both quantitatively and qualitatively, because of the familiar and "private" nature of the phenomenon. The only available figure estimates that the Italian municipalities' social services follow nearly 100.000 maltreated or neglected children every year, which is approximately 9.5 out of every 1.000 resident minors. This figure is probably an underestimate of the true prevalence, considering that the WHO - Regional Office for Europe (2013) has calculated that for every known case of child maltreatment/neglect, there are at least 9 additional cases that are not reported. An efficient system of welfare services for children can certainly identify some of the cases of maltreatment and neglect, but the most effective course of action to protect children who are not reached by social services consists of prevention and intervention with respect to the mitigation of risk factors. In Italy, there are no indicators of maltreatment on a regional basis, and the indicators used for adults refer to risk factors affecting adults.

Italian public policies, already burdened by the economic crisis, must also come to terms with the national public debt, which is the third largest in the world after that of the United States and Japan. This issue makes it difficult to sustain an adequate welfare system and address both the economic impact produced by the crisis and specific social problems, such as child abuse and neglect. The result of the demographic and economic crisis can be represented by the small number of resources dedicated to social policies for families and minors, who represent only $1.5 \%$ of Gross Domestic Production (GDP), which places Italy at the 16th position in the European classification. The Italian welfare system can be defined as both familyist and universalist: familyist because it still requires a strong commitment (by women in particular) to care for children and elderly adults; universalist because access to health and social services is guaranteed to all people who meet specific service requirements.

The Italian health system was reformed in 1978 to focus on prevention, the fight against exclusion, and the integration of social services and health care. The Italian social services were reformed in the year 2000 with L. 328/2000. This law entails the realization of an integrated system of social services. In particular, social service has recently moved from the exclusive protection of the child to the need to support the entire family. In the overall framework of the L.328/2000, a prominent role is assigned to the 7,982 Italian municipalities that are responsible for the social services of the territory, especially services for families and minors, working in synergy with the health services of the National Health Service.

\section{RESEARCH AIMS}

The purpose of this study is to present the first findings of vulnerability to neglect among minors in Italy to achieve a more comprehensive understanding of this phenomenon. The present study addresses the important issue of quantifying the risk of child maltreatment and neglect.

The research proposes the application of a new General Index on Vulnerability to Maltreatment and Neglect of minors based on a set of indicators that already exist at the regional and national levels. These indicators of the risk of neglect and abuse have been compared to the capacity of local policies to offer territorial services. The research was sponsored by Cesvi, an independent Italian NGO, working since 1985 to prevent abuse in children.

The General Index on Vulnerability to Maltreatment and Neglect summarizes both the weaknesses of territory in terms 
of risk factors and its ability to react in terms of policies and public services. Therefore, it measures the vulnerability of minors to the context's ability to protect them, combining a regional indicator of risk factors and of prevention policies and services.

Through the application of the new General Index on Vulnerability to Maltreatment and Neglect, the study compares the 20 Italian regions aiming to answer the following main questions: How much is every region exposed to child abuse in comparison with the other regions? Are local policies and services able to prevent child maltreatment while tackling the socio-economic problems of a territory that are related to specific risk factors? The capacity of local governments to protect children from neglect and maltreatment that arises from the comparison between the context index (risk factor analysis) and the policies and services index.

\section{DATA AND METHODS}

The General Index on Vulnerability to Maltreatment and Neglect consists of a descending ranking of regions: topranking regions are those that present a comparatively low risk of child maltreatment/neglect and, at the same time, offer a comparatively high level of local services and policies to prevent the problem.

The General Index on Vulnerability to Maltreatment and Neglect is the result of the aggregation of 65 indicators (as per Table 1), retrieved from The National Italian Statistic Institute, concerning risk factors and the social services offered in the various regions. Indicators related to child maltreatment/neglect risk factors were selected from the National Statistics Institute database based on their correspondence to the classification of risk factors proposed by the previously mentioned European Report on Preventing Child Maltreatment.

The methodological steps followed to calculate the General Index, and the detailed indicators are as follows:

- the selection of 65 territorial indicators with respect to the literature on risk factors and prevention associated policies/services (for example: regional indicator on poverty, unemployment, and percentage of pediatricians in the regions)

- The indicators are classified with respect to the following:

- Capacity (for example, the regional unemployment indicator relates to the ability to work; the regional indicator on the percentage of pediatricians in the territories relates to the ability to live a healthy life);

- The distinction between risk factors/symptoms and services; or

- The distinction between adults/potentially abusive and potentially abused children.

- The aggregate index for each category under examination was constructed through the application of the QUARS algorithm for each indicator, and the averages of all the regional indicators were calculated and sorted in a descending order.
Once the various indicators were made comparable, a macro-indicator was calculated for each area as a simple average of the sub-indicators.

The indicators related to the social services provided in the territories were identified on the basis of their pertinence to various risk factors and were selected from the National Statistics Institute survey on "Interventions and social services for single or associated municipalities" [62].

A bottom-up process was followed to identify the statistical indicators that could best describe the risk factors and, with respect to these indicators, those that could best represent the public services responsible for preventing and addressing risk factors. Subsequently, these indicators were classified by capacity in relation to their relevance to each of the risk factors. The 65 indicators were classified as follows (Table 1):

- Six capacities, according to the theory of the capability approach from the perspective of human development,

- Risk factors and social services indicators, and

- Indicators relating to potential adult perpetrators and potential child victims.

The choice of the capabilities' classification derives from the capabilities' approach to human development. In line with Sen's capability approach theory, the following were considered: taking care of oneself and others; living a healthy life; living a safe life; and gaining knowledge, access to resources and services. As shown in Table 1, data about potential child victims are available only for risk factors concerning living a healthy life and social services related to the capability of care and living a healthy life.

The indicators used for risk factors are all weighted for the reference population for each indicator (e.g., the unemployment rate is the number of employees compared to the total workforce); then, they describe the context variables on different dimensions, often relating to adults, which would not be relevant to weighing against the population of children.

Once the classification process was completed, an algorithm was applied to the indicators enabling comparisons among the regions and between each region and the national average.

The choice of the algorithm to be used was guided by the need to use a calculation method that has already been effectively tested in similar situations involving the classification of regional data [63]. The result of the elaborations, therefore, does not allow us to say in absolute terms which region works well, and which does not; rather, it can only determine which works best and which functions worse in relation to the other regions taken into consideration and with respect to the national average.

\subsection{Data Analysis}

The General Index on Vulnerability to Maltreatment and Neglect was completed through the following:

- The application of a formula of standardization for each of The 65 indicators, 
- The aggregation of standardized indicators in the six capabilities and the arithmetic mean for each of them,

- General arithmetic mean of all capabilities involved, applied to the general index and the four sub-indexes, and

- The presentation in descending order of regional results.

The index calculation method was inspired by the QUARS Index, an Italian index measuring the quality of regional development, promoted by a large number of local authorities and independent NGOs [63]. This statistical methodology has the merit of making indicators with different units of measurement comparable. It eliminates the distortion that is determined using the values assumed by the extremes of the distribution (i.e., the values of the regions with the highest and lowest indicator). This algorithm gives the same weight to all indicators and classes of indicators used: a choice that was made to avoid giving different weights based on researchers' decisions. The analysis of the literature has not produced enough information to weigh the various indicators on their different impacts on child abuse and neglect. For this reason, giving the same weight to all indicators was the least biased and most objective choice. This lack of weighting is mitigated by a variety and a large number of indicators used.

Using the QUARS algorithm, it was therefore decided to standardize each of the 65 indicators in such a way as to have a mean of zero (corresponding to the national average) and the same order of magnitude.

The standardization process has adopted the following transformation:

$$
\frac{Z_{i, J}=X_{i, J}-\mu}{\sigma_{X J}}
$$

Which means the following:

$\boldsymbol{X}_{i, j}$ regional data ${ }^{i}$ related to the variable ${ }^{j} \boldsymbol{\mu}_{J}$ is the mean among the values of all regions per variable ${ }^{j} \sigma_{X J}$ is the standard deviation of variable distribution ${ }^{j}$

\section{Table 1. Classification of 65 indicators used for the index}

\begin{tabular}{|c|c|}
\hline \multicolumn{2}{|c|}{ RISK FACTORS INDICATORS USED FOR THE INDEX } \\
\hline CHILDREN & $\begin{array}{l}\text { Capability: Living a healthy life } \\
\text { Early pregnancies, childhood obesity, adolescent smokers, underage drinking, adolescent drug users }\end{array}$ \\
\hline ADULTS & 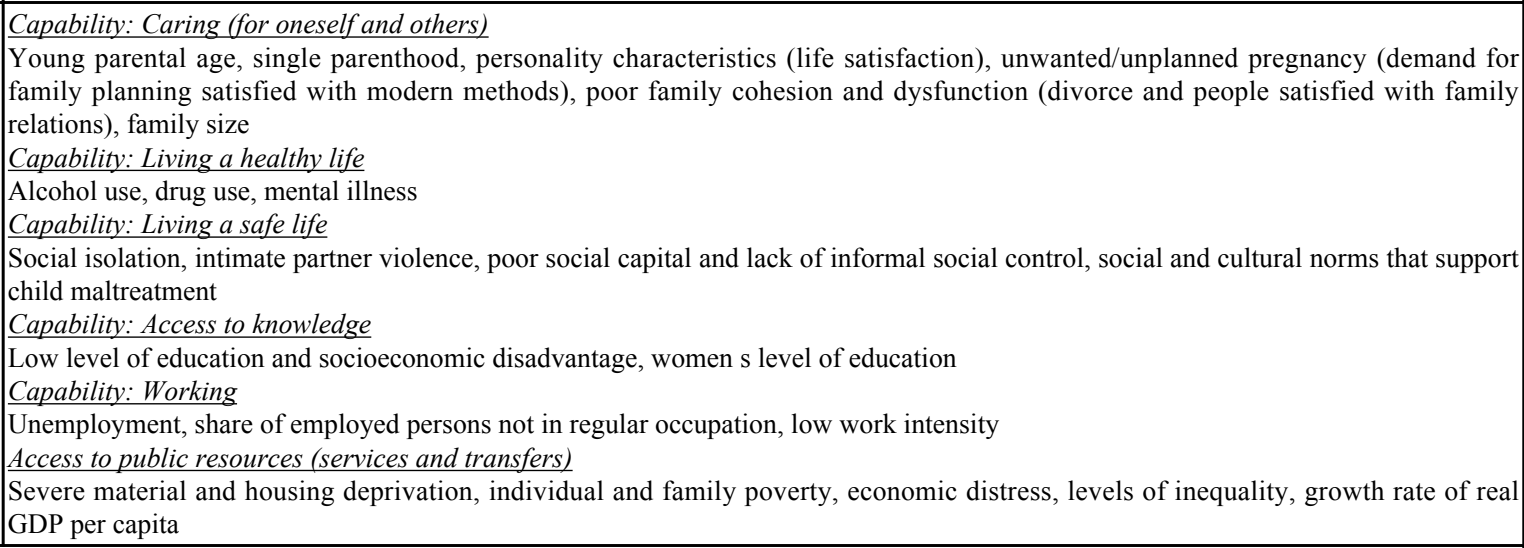 \\
\hline & RVICES INDICATORS USED FOR THE INDEX \\
\hline CHIL & $\begin{array}{l}\text { Capability: Caring (for oneself and others) } \\
\text { Participation in early childhood education, childcare services, minor guests of social and health care residential facilities, } \\
\text { socioeducational school support } \\
\text { Capability: Living a healthy life } \\
\text { Mental health services for young people ( } 0 \text { - } 17 \text { years old), medical assistance (pediatricians), support for motherhood (counseling) }\end{array}$ \\
\hline ADULTS & $\begin{array}{l}\text { Capability: Caring (for oneself and others) } \\
\text { Support for motherhood (pregnant or mothers guests of social and health care residential facilities and family centers), activities to } \\
\text { support parenthood, social services for families and children (professional social work, social home care, residential and } \\
\text { semiresidential structures) } \\
\text { Capability: Living a healthy life } \\
\text { Hospital discharges for mental disorders (alcohol/substance related) and mood disorders, patients in addiction treatment centers, } \\
\text { outpatient and residential facilities for psychiatric care and mental health care, users of municipal social services for addictions } \\
\text { Capability: Living a safe life } \\
\text { Guests of social and health care residential facilities involved in criminal proceedings (adults), anti-violence centers and shelters, } \\
\text { services for social inclusion } \\
\text { Capability: Access to knowledge } \\
\text { Participation of unemployed adults in formal and/or nonformal education } \\
\text { Capability: Working } \\
\text { Users of municipal social services on the support for employment } \\
\text { Access to public resources (services and transfers) } \\
\text { Municinal }\end{array}$ \\
\hline
\end{tabular}


In other words, it is the average of differences in values of all the regions from the average of the variable. This value is used to quantify the interval within which the variable data are distributed. The value of the standard deviation is the same for all values related to a variable.

$\mathrm{Z} i, \mathrm{j}$ is the data of region $\mathrm{i}$ relative to the standardized $\mathrm{j}$ variable. Each $\mathrm{X} \mathrm{i}, \mathrm{j}$ corresponds to one and only one $\mathrm{Z} \mathrm{i,j}$; moreover, the distances are preserved by construction.

The standardization procedure, therefore, allowed for the difference between the regional data relative to a given variable and the average of all regions for the same variable, all compared to the average quadratic deviation or standard deviation of the distribution of the variable itself. Subsequently, the average between the comparable standardized values was also averaged. The simple average was calculated first among the variables that make up each macro-indicator to arrive at the final synthesis value among the macro-indicators.

The index calculation method enabled us to read data at multiple levels:
- The ranking of each region in the overall classification of the 20 Italian regions and comparison to the national average, and

- The ranking of each region into a territorial map comparing the intersection of risk factors and services.

\section{RESULTS}

The regional index on children vulnerable to abuse and neglect, the first element of this analysis, was calculated for each individual region and is presented in Fig. (1) through different color intensities.

To facilitate the interpretation, a number indicates the regional ranking in the overall classification. The southern regions are found to have the least satisfactory balance between risk factors and social services. Since the final indicator includes both risk factors and social services, in this way, a synthetic vision between the risk/critical factors of the territory and its ability to respond in terms of the offer of social services can be obtained.

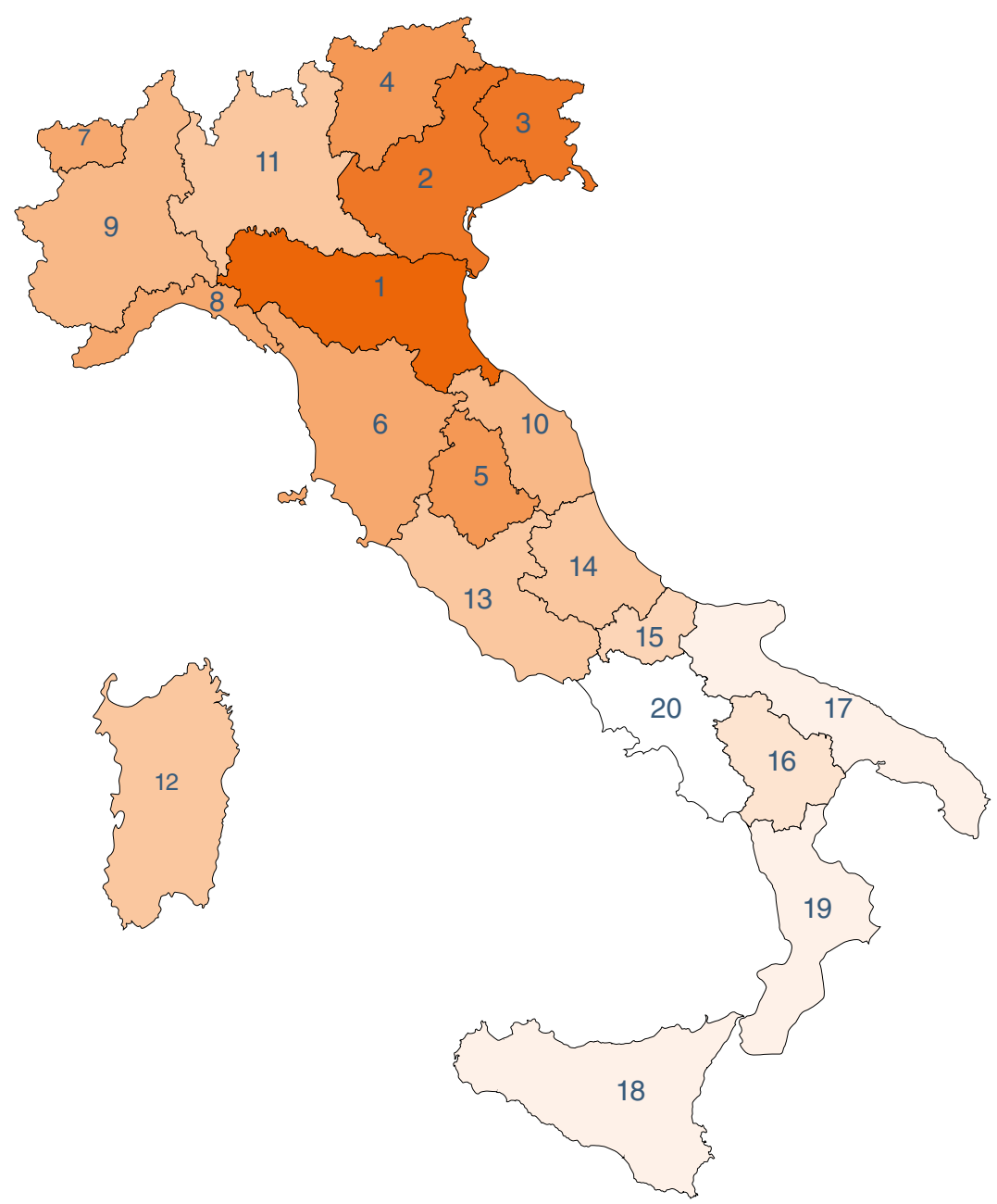

Fig. (1). Italian territorial map comparing the intersection of risk factors and social services. 


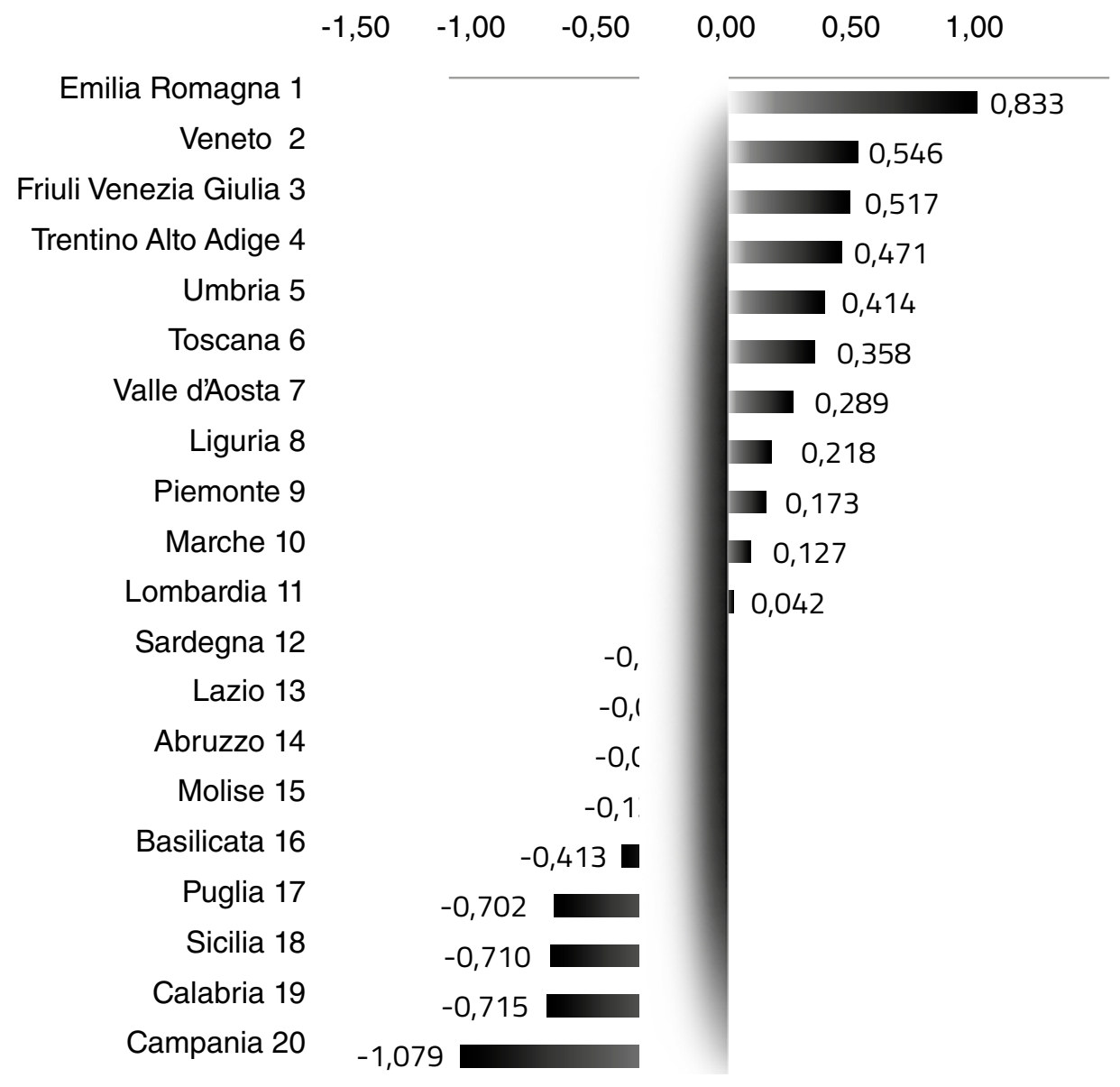

Fig. (2). The regional index on children vulnerable to abuse compared to the specific risk factors and services.

One of the aims listed was to determine whether local social services are able to solve the issues found in the respective regions. In Fig. (2), it is possible to see this imbalance in more detail. The General Index on Vulnerability to Maltreatment and Neglect, which summarizes the indicators of risk factors and social services, ranks eleven regions above the national average, including seven regions in northern Italy and four regions in central Italy.

The 1st position, which is significantly higher than the other regions, is occupied by Emilia Romagna, in particular with regard to caring and working capabilities. Regions ranking first in various capabilities are as follows: Friuli Venezia Giulia region in the capability of access to resources, Trentino Alto Adige in the capability of education and knowledge, Valle d'Aosta in the capability of safety, and Liguria in the capability of health.

The high ranking of the first regions is the result of an average of six capabilities and, therefore, identifies both the strong points of the top positions for each capability and the overall balance between the capabilities as a whole. Veneto region, for example, despite being 2 nd in the general index, does not rank in 1 st position in any capability: its final position is due to the good overall balance on all the aspects examined.

The last four regions in the index, in terms of risk of child neglect and maltreatment, are Campania, Calabria, Sicilia and Puglia. They rank from the 16th to the 20th position in all capabilities, confirming a structural criticality in their social and welfare systems in relation to this issue. A partial exception is represented by Sicilia, which ranks 10th due to its high ranking on the capability of safety (Table 2).

This variability between northern and southern Italy could reflect the difficulties of the South that could be related to historical, cultural, social, and economic reasons. Table 2 gives details of capacity and final rankings that offer the opportunity to deepen the strengths and weaknesses of each region. The number in the table indicates the position of the region in the ranking for each individual capacity.

The territorial mapping of risk factors and social services led to the identification of 4 different clusters combining different levels of risk factors (low or high critical context) and social services indicators (low or high level of services):

- Highly critical regions with high levels of risk factors without a high response in terms of social services provided by local administrations; 
Table 2. Regional index of children maltreatment prevention and care, divided by capability.

\begin{tabular}{|c|c|c|c|c|c|c|}
\hline & $\frac{\text { Caring (for oneself }}{\text { and others) }}$ & Living a healthy life & $\underline{\text { Living a safe life }}$ & Access to knowledge & Working & $\frac{\text { Access to public }}{\text { resources }}$ \\
\hline $\begin{array}{l}\text { Emilia Romagna } \\
0,833\end{array}$ & 1 & 8 & 2 & 9 & 1 & 4 \\
\hline \begin{tabular}{|l|} 
Veneto \\
0,546 \\
\end{tabular} & 6 & 4 & 3 & 12 & 2 & 2 \\
\hline $\begin{array}{l}\text { Friuli Venezia Giulia } \\
0,517\end{array}$ & 11 & 9 & 8 & 6 & 5 & 1 \\
\hline \begin{tabular}{|l|} 
Trentino Alto Adige \\
0,471
\end{tabular} & 3 & 3 & 4 & 1 & 8 & 8 \\
\hline $\begin{array}{l}\text { Umbria } \\
0,414\end{array}$ & 7 & 7 & 7 & 7 & 3 & 7 \\
\hline $\begin{array}{l}\text { Toscana } \\
0,358 \\
\end{array}$ & 8 & 5 & 11 & 2 & 10 & 5 \\
\hline $\begin{array}{l}\text { Valle d } \square \text { Aosta } \\
0,289\end{array}$ & 4 & 2 & 1 & 15 & 7 & 6 \\
\hline \begin{tabular}{|l|} 
Liguria \\
0,218 \\
\end{tabular} & 2 & 1 & 9 & 13 & 4 & 11 \\
\hline $\begin{array}{l}\text { Piemonte } \\
0,173\end{array}$ & 5 & 15 & 14 & 11 & 6 & 3 \\
\hline $\begin{array}{l}\text { Marche } \\
0,127\end{array}$ & 12 & 12 & 5 & 8 & 11 & 9 \\
\hline $\begin{array}{l}\text { Lombardia } \\
0,042 \\
\end{array}$ & 10 & 13 & 12 & 10 & 9 & 10 \\
\hline $\begin{array}{l}\text { Sardegna } \\
-0,060\end{array}$ & 9 & 10 & 6 & 16 & 12 & 14 \\
\hline \begin{tabular}{|l|} 
Lazio \\
$-0,080$ \\
\end{tabular} & 16 & 6 & 20 & 4 & 13 & 12 \\
\hline \begin{tabular}{|l|} 
Abruzzo \\
-0.090 \\
\end{tabular} & 14 & 11 & 13 & 5 & 14 & 15 \\
\hline $\begin{array}{l}\text { Molise } \\
-0,138\end{array}$ & 15 & 14 & 17 & 3 & 15 & 13 \\
\hline $\begin{array}{l}\text { Basilicata } \\
-0,413\end{array}$ & 13 & 19 & 15 & 14 & 16 & 16 \\
\hline $\begin{array}{l}\text { Puglia } \\
-0,702\end{array}$ & 18 & 17 & 19 & 18 & 17 & 17 \\
\hline \begin{tabular}{|l} 
Sicilia \\
$-0,710$
\end{tabular} & 17 & 16 & 10 & 20 & 18 & 19 \\
\hline \begin{tabular}{|l|} 
Calabria \\
$-0,715$ \\
\end{tabular} & 19 & 18 & 16 & 17 & 19 & 18 \\
\hline $\begin{array}{l}\text { Campania } \\
-1,079\end{array}$ & 20 & 20 & 18 & 19 & 20 & 20 \\
\hline
\end{tabular}

- Reactive regions, or territories that, despite having high risk factors, also have a high capability for response through social services;

- Virtuous regions, or territories that enjoy low risk factors but have a high level of social services; and

- Stable regions, or territories that show a low level of risk factors but also have a low level of social services.

The idea behind the clusters is that the regional territories differ both in the presence of risk factors in the context and in the choice of greater or lesser investment in services. In this sense, the regions that present a adequate system of policies and services, to prevent the phenomenon of maltreatment, are considered virtuous or reactive in relation to the presence of low or high risk factors.

Similarly, the idea of stability is associated with the scarcity of demand (risk factors) and supply (services).

Fig. (3) presents the positions of different regions inside these clusters. On the $\mathrm{x}$-axis, there is a measure of services with a score that ranges from 20 to 0 in decreasing order, where 20 indicates the worse possible score; on the y-axis, there is a measure of context with the same range of scores. The territorial map of risk factors and social services includes all the southern regions, except Sardegna, which are highly critical. Within this cluster, various situations, ranging from the highest criticality level to situations closer to the national average, were observed. 


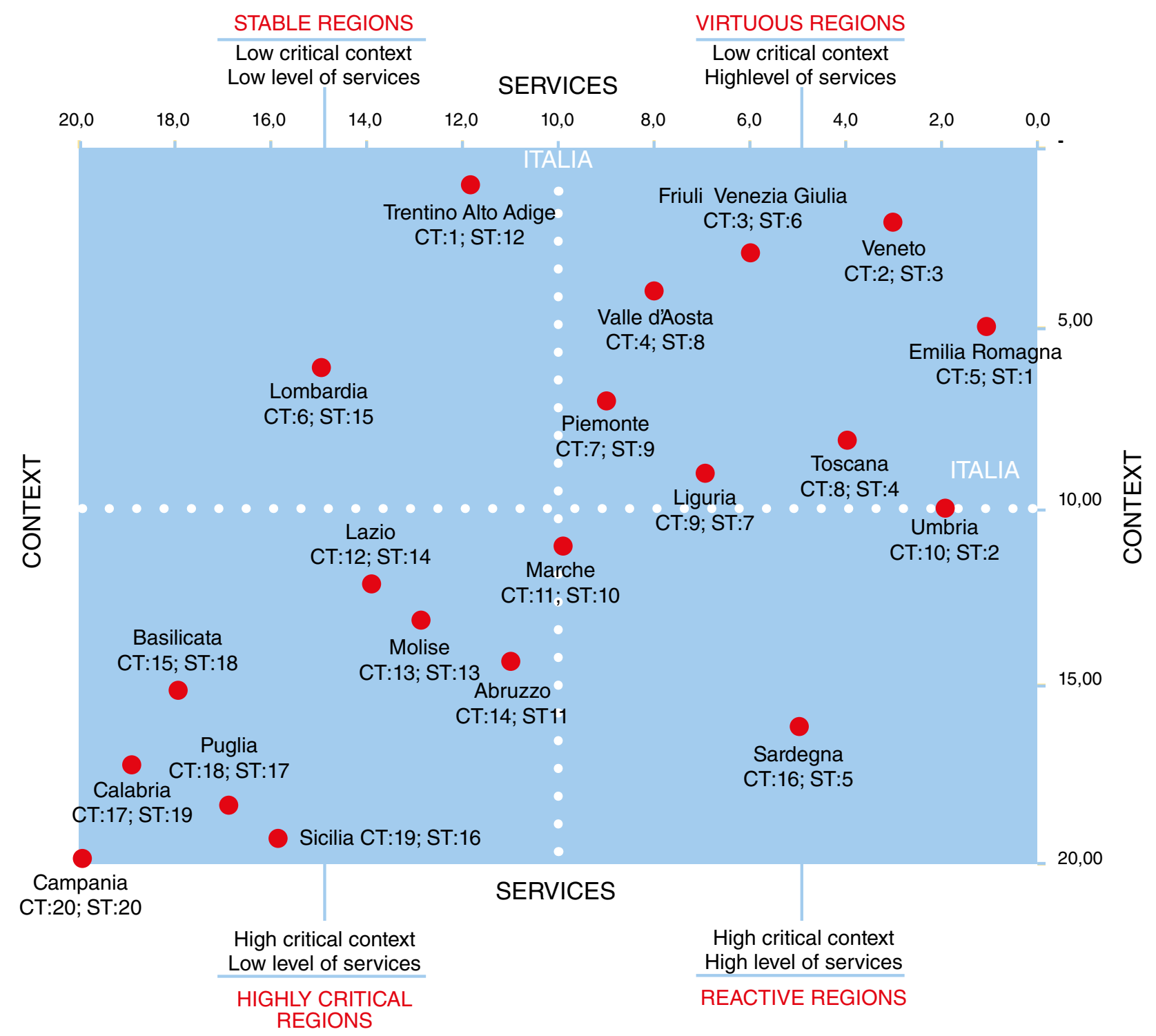

Fig. (3). Cluster analysis map combining different levels of risk factors and social services indicators.

The cluster of reactive regions mainly concerns Sardegna, a southern region that, in the 16 th position in terms of the risk factors index, responds with a social services system that ranks in the 5 th position in Italy.

Among the virtuous regions, which have a low risk factors index and a social services index higher than the national average, are seven of the eight regions of northern Italy and one from central Italy (Toscana). Even in this cluster, the ranking varies among most virtuous regions and regions, which are closer to the national average.

Among the stable cluster regions are two northern regions. Both cases concern regions that face a low risk factors index and provide a level of services that ranks lower than the national average.

\section{DISCUSSION}

The key added value of this study is the proposal of a regional and a national indicator to provide awareness and a greater ability to monitor the phenomenon of child neglect in Italy. This study highlights the importance of collecting data in a systematic way. The proposed General Index on Vulnerability to Maltreatment and Neglect represents the first attempt, at a national level, to conduct a comparative study on territorial vulnerability and the potential to respond to child abuse and neglect; this study was developed with particular rigor in the design of the method of calculation and analysis. The proposed index can also be useful to track regional progress in terms of the risk of falling into child neglect and resilience processes, in line with contributions to the development literature [60].

A large amount of information in the survey relies on the 65 indicators used for the calculation of the final index and the classification of the six capabilities, which offer important points for reflection on the strengths and weaknesses of each territory. 
In reactive regions, authorities are fighting against the risks, however, this could have different meanings: it could mean that in this region the risk indicators have stimulated administrations to raise the level of services (which were previously low) and that the administration is currently trying to counter the risk. This could reflect the ability to react in terms of policies and public services of these territories. However, it could also mean that the administration has a high level of services which, however, have not been able to counter the risk so far and that these services may be inefficient or have weaknesses.

The possibility to use a standardized index to repeat surveys over time could help administrators to understand the effectiveness of the activated services.

In virtuous regions, authorities invest in policies even if there are low risk indicators, and this could suggest a prevention culture with which professionals might focus on child and family well-being. On the other hand, it is possible that in these territories, administration activated a high level of services that effectively fight the risk.

Highly critical regions represent disadvantaged communities that lack adequate services even if there are a lot of risk indicators that could have implications for psychological, educational, and vocational children functioning in future years.

In a stable region, the lack of risk could reduce the need for interventions that aim to reduce it and to enhance protection at the individual, familial, and community levels. This balanced situation doesn't promote a change, therefore, these regions are stable in their functioning. The major socio-economic difficulties of the southern regions translate to a greater degree of vulnerability to child maltreatment. For these territories, it is important to choose to build constructive strategies for the system. Northern regions could help in exchanging best practices, tools, and processes. By combining factors within a comprehensive ecological framework, the present work highlights the strong link between the social and economic condition of the population of the territories, in terms of social services, and the risk factors connected to the maltreatment and neglect of children. Since specific indicators of child abuse were unavailable and only indicators concerning the risk factors and services were truly at our disposal, the index can only express the potential vulnerability to child maltreatment and neglect of one territory compared to the others but cannot measure the actual level of child maltreatment or neglect. The lack of data already existing at the regional and national levels emerges as the main weakness, as it limits the ability of the index to represent the phenomenon in all its aspects. The national statistical system does not provide specific data on either the target of parenthood or the target of families at higher risk of child maltreatment and neglect. Where available, indicators related to parental age were selected, but the national statistical system remains very poor for this issue: many indicators are derived from sample national surveys that do not guarantee statistical representativeness for more in-depth analysis at the regional level.

There were limitations to this study. The lack of data has also affected the parts of the index related to services and local policies. In fact, the national survey on social services of the municipalities does not allow for the identification of services provided to families and children related to the specific problem of child maltreatment and neglect. This survey generically defines the social services provided by municipalities as "services for families and children", without the possibility of distinguishing between adults and minors. Additionally, the reasons for the intervention of social services are not monitored, for example, whether they are due to economic conditions or violence and abuse.

Here again, the national statistical system does not provide for this type of distinction, since data on services intended specifically for child maltreatment and neglect are not collected.

Considering the strengths and limitations of the General Index on Vulnerability to Maltreatment and Neglect as a whole, it is possible to say that it represents significant progress in child abuse studies since it is a rich and detailed information tool based on indicators that the national statistical system already provides, which are updated regularly.

At the same time, the need to provide more detailed data and other indicators emerges with greater urgency to broaden the spectrum of information that the index is able to offer, reaching a systematic analysis of the real and specific size of the phenomenon, limited not only to the potential comparative vulnerability of the territories to child abuse.

This index gives policymakers information on where to direct their efforts to prevent child maltreatment. In the case of Sicilia, for example, political decision makers can become aware that social services are lacking in this area. Therefore, they could take more targeted action.

The work on indicators has been strongly affected by the lack of specific territorial data that can offer an existing framework of the phenomenon in question. In fact, social work is characterized by a difficulty in collecting useful data and, at the same time, the difficulty in promoting a reflection on practices starting from working professionals.

\section{CONCLUSION}

While research has accumulated in the fields of risk factors, the concept, findings, and measures developed in child neglect prevention have had little penetration into the research field and in the policy discussion [64]. However, even if data on abuse is lacking, none can reflect on the data that are available. The number of children in the care of services already indicates a problem; however, greater knowledge of the elements of risk would allow for a better understanding of the phenomenon. This analytical process could offer important policy recommendations at a national level, highlighting the strengths and weaknesses of the various territories. Knowledge of the risk factors and their effects is vital for improving clinical practices aimed at preventing child maltreatment and neglect. The proper care needs of high-risk children and their families can thereby be better targeted to prevent child neglect [7]. This emphasizes the responsibility for adults and institutions with roles in ensuring the safety of the children 
under their care.

\section{ETHICS APPROVAL AND CONSENT TO PARTI- CIPATE}

Not applicable.

\section{HUMAN AND ANIMAL RIGHTS}

No humans and animals were directly involved in this research.

\section{CONSENT FOR PUBLICATION}

Not applicable.

\section{AVAILABILITY OF DATA AND MATERIALS}

The data shall be shared on request by the corresponding author [P.C] upon reasonable request.

\section{FUNDING}

None.

\section{CONFLICT OF INTEREST}

The authors declare no conflict of interest, financial or otherwise.

\section{ACKNOWLEDGEMENTS}

Declared none.

\section{REFERENCES}

[1] Kesner JE. Self-reports of child maltreatment in the U.S.: A key social indicator. Soc Indic Res 2007; 83(1): 117-24. [http://dx.doi.org/10.1007/s11205-006-9064-4] [PMID: 20076776]

[2] Bollini A, Giannotta F, Angeli A. Maltrattamento sui bambini: Quante le vittime in Italia? [Internet] 2013.http://www.garanteinfanzia.org/ sites/default/files/documenti/dossier-bambini-maltrattati-tdhcismai.pdf

[3] Hildyard KL, Wolfe DA. Child neglect: Developmental issues and outcomes. Child Abuse Negl 2002; 26(6-7): 679-95.

[http://dx.doi.org/10.1016/S0145-2134(02)00341-1] [PMID: 12201162]

[4] Gauthier L, Stollak G, Mess? L, Aronoff J. Recall of childhood neglect and physical abuse as differential predictors of current psychological functioning. Child Abuse Negl 1996; 20(7): 549-59.

[http://dx.doi.org/10.1016/0145-2134(96)00043-9] [PMID: 8832112]

[5] Welch GL, Bonner BL. Fatal child neglect: Characteristics, causation, and strategies for prevention. Child Abuse Negl 2013; 37(10): 745-52. [http://dx.doi.org/10.1016/j.chiabu.2013.05.008] [PMID: 23876861]

[6] Mennen FE, Kim K, Sang J, Trickett PK. Child neglect: Definition and identification of youth's experiences in official reports of maltreatment. Child Abuse Negl 2010; 34(9): 647-58. [http://dx.doi.org/10.1016/j.chiabu.2010.02.007] [PMID: 20643482]

[7] Mulder TM, Kuiper KC, van der Put CE, Stams GJM, Assink M. Risk factors for child neglect: A meta-analytic review. Child Abuse Negl 2018; 77(January): 198-210.

[http://dx.doi.org/10.1016/j.chiabu.2018.01.006] [PMID: 29358122]

[8] Wolock I, Horowitz B. Child maltreatment as a social problem: The neglect of neglect. Am J Orthopsychiatry 1984; 54(4): 530-43. [http://dx.doi.org/10.1111/j.1939-0025.1984.tb01524.x] [PMID: 6507592]

[9] Norman RE, Byambaa M, De R, Butchart A, Scott J, Vos T. The longterm health consequences of child physical abuse, emotional abuse, and neglect: A systematic review and meta-analysis. PLoS Med 2012; 9(11)e1001349

[http://dx.doi.org/10.1371/journal.pmed.1001349] [PMID: 23209385]

[10] McDonell JR. Neighborhood characteristics, parenting, and children's safety. Soc Indic Res 2007; 83(1): 177-99.

[http://dx.doi.org/10.1007/s11205-006-9063-5]

[11] Petersen AC, Joseph J, Feit M. New directions in child abuse and neglect research. 2014

[12] Ayala-Nunes L, Jimnez L, Jesus S, Nunes C, Hidalgo V. A ecologica model of well-being in child welfare referred children. Soc Indic Res 2018; 140(2): 811-36.

[http://dx.doi.org/10.1007/s11205-017-1807-x]

[13] Nasir A, Zimmer A, Taylor D, Santo J. Psychosocial assessment of the family in the clinical setting. BMC Psychol 2019; 7(1): 3 [http://dx.doi.org/10.1186/s40359-018-0277-5] [PMID: 30635046]

[14] Bronfenbrenner U. Ecological systems theory.Six theories of child development: Revised formulations and current issues. London, England: Jessica Kingsley Publishers 1992; pp. 187-249.

[15] Dubowitz H, Lane WG, Semiatin JN, Magder LS, Venepally M, Jans M. The safe environment for every kid model: Impact on pediatric primary care professionals. Pediatrics 2011; 127(4): e962-70. [http://dx.doi.org/10.1542/peds.2010-1845] [PMID: 21444590]

[16] Elliott K, Urquiza A. Ethnicity, Culture, and Child Maltreatment. J Soc Issues 2006; 62(4): 787-809. [http://dx.doi.org/10.1111/j.1540-4560.2006.00487.x]

[17] Bornstein MH, Haynes OM, Azuma H, et al. A cross-national study of self-evaluations and attributions in parenting: Argentina, Belgium, France, Israel, Italy, Japan, and the United States. Dev Psychol 1998; 34(4): 662-76.

[http://dx.doi.org/10.1037/0012-1649.34.4.662] [PMID: 9681258]

[18] Ards SD, Myers SL Jr, Ray P, Kim HE, Monroe K, Arteaga I. Racialized perceptions and child neglect. Child Youth Serv Rev 2012; 34(8): 1480-91. [Internet].

[http://dx.doi.org/10.1016/j.childyouth.2012.03.018] [PMID: 22904589]

[19] Williams SE. Redrawing the line: An exploration of how lay people construct child neglect. Child Abuse Negl 2017; 68: 11-24. [http://dx.doi.org/10.1016/j.chiabu.2017.03.014] [PMID: 28391074]

[20] East Sussex County Council. Neglect toolkit for practitioners. 2017.

[21] Levesque RJR. Child maltreatment and the law: Returning to first principles Child. 2008

[22] Rebbe R. What Is Neglect? State Legal Definitions in the United States. 2018.

[http://dx.doi.org/10.1177/1077559518767337]

[23] Stoltenborgh M, Bakermans-Kranenburg MJ, van Ijzendoorn MH. The neglect of child neglect: A meta-analytic review of the prevalence of neglect. Soc Psychiatry Psychiatr Epidemiol 2013; 48(3): 345-55. [http://dx.doi.org/10.1007/s00127-012-0549-y] [PMID: 22797133]

[24] Boulware LE, Cooper LA, Ratner LE, LaVeist TA, Powe NR. Race and trust in the health care system. Public Health Rep 2003; 118(4): 358-65.

[http://dx.doi.org/10.1016/S0033-3549(04)50262-5]

[PMID: 12815085]

[25] Jonson-Reid M, Drake B, Chung S, Way I. Cross-type recidivism among child maltreatment victims and perpetrators. Child Abuse Negl 2003; 27(8): 899-917.

[http://dx.doi.org/10.1016/S0145-2134(03)00138-8] [PMID: 12951139]

[26] Taylor J, Daniel B, Scott J. Noticing and helping the neglected child: Towards an international research agenda. Child Fam Soc Work 2012; 17(4): 416-26.

[http://dx.doi.org/10.1111/j.1365-2206.2011.00795.x]

[27] Zielinski S, Paradis HA, Herendeen P, Barbel P. The identification of psychosocial risk factors associated with child neglect using the wecare screening tool in a high-risk population. J Pediatr Health Care 2017; 31(4): 470-5.

[http://dx.doi.org/10.1016/j.pedhc.2016.12.005] [PMID: 28189398]

[28] Schumacher JA, Slep AMS, Heyman RE. Risk factors for child neglect. Aggress Violent Behav 2001; 6(23): 231-54 [http://dx.doi.org/10.1016/S1359-1789(00)00024-0]

[29] Berzenski SR, Bennett DS, Marini VA, Sullivan MW, Lewis M. The role of parental distress in moderating the influence of child neglect on maladjustment. J Child Fam Stud 2014; 23(8): 1325-36.

[http://dx.doi.org/10.1007/s10826-013-9791-5] [PMID: 25346589]

[30] Clment M, Brub A, Chamberland C. Prevalence and risk factors of child neglect in the general population. Public Health 2016; 138: 86-92.

[http://dx.doi.org/10.1016/j.puhe.2016.03.018] [PMID: 27117500]

[31] Sethi D, Alink L, Barnekow V, Bellis M, Butchart A, Gilbert R, et al. European report on preventing child maltreatment [Internet] WHO Regional Office for Europe 2013.http://www.euro.who.int/_data/ assets/pdf_file/0019/217018/European-Report-on-Preventing-ChildMaltreatment.pdf?ua=1

[32] Stith SM, Liu T, Davies LC, et al. Risk factors in child maltreatment: 
A meta-analytic review of the literature. Aggress Violent Behav [Internet]

[http://dx.doi.org/10.1016/j.avb.2006.03.006]

[33] Migliorini L, Rania N, Cavanna D, Cardinali P, Guiducci V. Comparing maltreating and foster families in italy. J Child Fam Stud

[34] Li F, Godinet MT, Arnsberger P. Protective factors among families with children at risk of maltreatment: Follow up to early school years. Child Youth Serv Rev 2011; 33(1): 139-48. [Internet].

[http://dx.doi.org/10.1016/j.childyouth.2010.08.026]

[35] Laslett A, Room R, Dietze P, Ferris J. Alcohol's involvement in recurrent child abuse and neglect cases 2012; 1786-93.

[http://dx.doi.org/10.1111/j.1360-0443.2012.03917.x]

[36] Freisthler B, Wolf JP, Wiegmann W, Kepple NJ. Drug use, the drug environment, and child physical abuse and neglect. Child Maltreat 2017; 22(3): 245-55

[http://dx.doi.org/10.1177/1077559517711042] [PMID: 28592146]

[37] Lee SJ, Taylor CA, Bellamy JL. Paternal depression and risk for child neglect in father-involved families of young children. Child Abuse Negl 2012; 36(5): 461-9.

[http://dx.doi.org/10.1016/j.chiabu.2012.04.002] [PMID: 22633873]

[38] Schneider W. Single mothers, the role of fathers, and the risk for child maltreatment.

[http://dx.doi.org/10.1016/j.childyouth.2017.07.025]

[39] Cardinali P, Migliorini L, Giribone F, Bizzi F, Cavanna D. Domestic violence in separated couples in Italian Context: Communalities and singularities of women and men experiences. Front Psychol 2018; 9(SEP): 1602

[http://dx.doi.org/10.3389/fpsyg.2018.01602] [PMID: 30233457]

[40] Pelton LH. The continuing role of material factors in child maltreatment and placement. Child Abus Negl [Internet] 41: 30-9. [http://dx.doi.org/10.1016/j.chiabu.2014.08.001]

[41] Anderson RE. And still WE rise: Parent-child relationships, resilience, and school readiness in low-income urban Black families. J Fam Psychol 2018; 32(1): 60-70.

[http://dx.doi.org/10.1037/fam0000348] [PMID: 28910130]

[42] Masten AS. Resilience Theory and Research on Children and Families: Past, Present, and Promise. J Fam Theory Rev 2018; 10(1): $12-31$.

[http://dx.doi.org/10.1111/jftr.12255]

[43] Heard-Garris N, Davis MM, Szilagyi M, Kan K. Childhood adversity and parent perceptions of child resilience. BMC Pediatr 2018; 18(1): 204.

[http://dx.doi.org/10.1186/s12887-018-1170-3] [PMID: 29945566]

[44] Van Wert M, Fallon B, Trocm N, Collin-Vzina D. Educational neglect: Understanding 20 years of child welfare trends. Child Abuse Negl 2018; 75(April): 50-60.

[http://dx.doi.org/10.1016/j.chiabu.2017.04.034] [PMID: 28528806]

[45] Ruiz-Casares M, Trocm N, Fallon B. Supervisory neglect and risk of harm. Evidence from the Canadian Child Welfare System. Child Abuse Negl 2012; 36(6): 471-80

[http://dx.doi.org/10.1016/j.chiabu.2012.03.005] [PMID: 22770635]

[46] Lloyd MH, Kepple NJ. Unpacking the parallel effects of parental alcohol misuse and low income on risk of supervisory neglect. Child Abuse Negl 2017; 69: 72-84.

[http://dx.doi.org/10.1016/j.chiabu.2017.03.007] [PMID: 28456067]

[47] Lefebvre R, Fallon B, Van Wert M, Filippelli J. Examining the relationship between economic hardship and child maltreatment using data from the Ontario incidence study of reported child abuse and neglect-2013 (OIS-2013). Behav Sci (Basel) 2017; 7(1)E6 [http://dx.doi.org/10.3390/bs7010006] [PMID: 28208690]

[48] Cohen S, Wills TA. Stress, social support, and the buffering hypothesis. US: American Psychological Association 1985; 98: pp. 310-57.

[49] Migliorini L, Rania N. La prevenzione primaria del disagio del minore e $1 \square$ ?? integrazione dei servizi: Il ruolo pivot dei pediatri di famiglia. Quad ACP 2016; 23(1): 26-7.

[50] Keeshin BR, Dubowitz H. Childhood neglect: The role of the paediatrician. Paediatr Child Health 2013; 18(8): e39-43. [PMID: 24426798]

[51] Slack KS, Berger LM, DuMont K, Yang MY, Kim B, Ehrhard-Dietzel $\mathrm{S}$, et al. Risk and protective factors for child neglect during early childhood: A cross-study comparison. Child Youth Serv Rev 2011; 33(8): 1354-63. [Internet].

[http://dx.doi.org/10.1016/j.childyouth.2011.04.024]

[52] Sen A. Dialogue capabilities, lists, and public reason: Continuing the conversation. Fem Econ 2004; 10(3): 77-80.

[http://dx.doi.org/10.1080/1354570042000315163]

[53] Sen A. Capability and well-being. The Philosophy of Economics: An Anthology 2007; pp. 270-94.

[http://dx.doi.org/10.1017/CBO9780511819025.019]

[54] Sen A. Development as Freedom. In: The Globalization and Development Reader John Wiley \& Sons. 2015.

[55] Nussbaum M. Women and Human Development: The Capabilities Approach Cambridge University Press. 2000; pp. xxi-312.

[56] Domnguez-Serrano M, del Moral Espn L. From relevant capabilities to relevant indicators: Defining an indicator system for children's wellbeing in spain. Child Indic Res 2018; 11(1): 1-25.

[http://dx.doi.org/10.1007/s12187-016-9415-x]

[57] Landers AL, McLuckie A, Cann R, et al. A scoping review of evidence-based interventions available to parents of maltreated children ages 0-5 involved with child welfare services. Child Abuse Negl 2018; 76(76): 546-60.

[http://dx.doi.org/10.1016/j.chiabu.2017.09.012] [PMID: 28985958]

[58] Casanueva C, Tueller S, Dolan M, Testa M, Smith K, Day O. Examining predictors of rereports and recurrence of child maltreatment using two national data sources. Child Youth Serv Rev 2015; 48: 1-13. [Internet].

[http://dx.doi.org/10.1016/j.childyouth.2014.10.006]

[59] Solomon D, ??sberg K, Peer S, Prince G. Cumulative risk hypothesis: Predicting and preventing child maltreatment recidivism. Child Abuse Negl 2016; 58: 80-90.

[http://dx.doi.org/10.1016/j.chiabu.2016.06.012] [PMID: 27352090]

[60] Mauro V, Biggeri M, Maggino F. Measuring and monitoring poverty and well-being: A new approach for the synthesis of multidimensionality. Soc Indic Res 2018; 135(1): 75-89. [http://dx.doi.org/10.1007/s11205-016-1484-1]

[61] OMS. Preventing injuries and violence: A guide for ministries of health

2007.whqlibdoc.who.int/publications/2007/9789241595254_eng.pdf

[62] ISTAT. Interventi e servizi sociali dei comuni singoli o associati. 2014.

[63] Gnesi C, Segre E, Villa A. Quars 2010. Come Si Vive in Italia 2010.

[64] Howard KS, Brooks-Gunn J. The role of home-visiting programs in preventing child abuse and neglect. Future Child 2009; 19(2): 119-46. [http://dx.doi.org/10.1353/foc.0.0032] [PMID: 19719025]

\section{C) 2020 Cardinali et al.}

This is an open access article distributed under the terms of the Creative Commons Attribution 4.0 International Public License (CC-BY 4.0), a copy of which is available at: (https://creativecommons.org/licenses/by/4.0/legalcode) This license permits unrestricted use, distribution, and reproduction in any medium, provided the original author and source are credited. 